\title{
MANAGEMENT OF SIMPLE BONE CYST WITH INTRACYSTIC CORTICOSTEROID INJECTION
}

\author{
S. Ramanathan ${ }^{1}$, S. Adbul Ajees ${ }^{2}$, D. Sivaraman ${ }^{3}$
}

${ }^{1}$ Associate Professor, Department of Orthopaedics, Thanjavur Medical College, Thanjavur. ${ }^{2}$ Assistant Professor, Department of Orthopaedics, Government Sivagangai Medical College. ${ }^{3}$ Assistant Surgeon, Government Head-Quarters Hospital, Perambalur.

HOW TO CITE THIS ARTICLE: Ramanathan S, Ajees SA, Sivaraman D. Management of simple bone cyst with intracystic corticosteroid injection. J. Evolution Med. Dent. Sci. 2017;6(66):4787-4789, DOI: 10.14260/Jemds/2017/1037

\section{PRESENTATION OF CASE}

A 14-year-old male child came with complaints of pain, which was progressive in nature followed by limping for past 4 months. On examination, patient had tenderness over right proximal thigh. All the movements of hip joints were normal. There was no neurovascular involvement and no significant limb length discrepancy.

On X-rays: $A P$ view showed centrally located, wellcircumscribed, radiolucent expansile lesion with narrow zone of transition and no matrix.(1) The regional cortex is thinned out. The lesion presented at juxta-epiphyseal portion of metaphysis of proximal femur,(2) right side (Fig. No. 1).

MRI: shows single cavity with central fluid collection.(3) No evidence of pathological fracture (Fig. No. 2) confirmed the diagnosis.

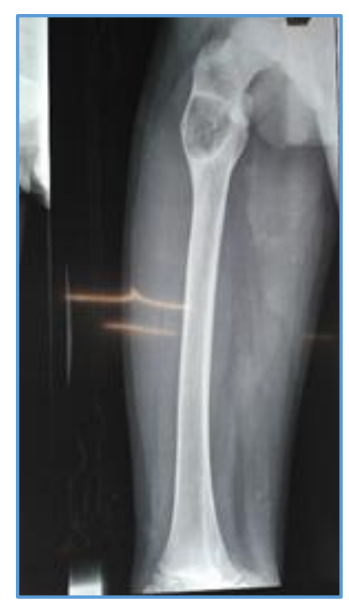

Figure 1

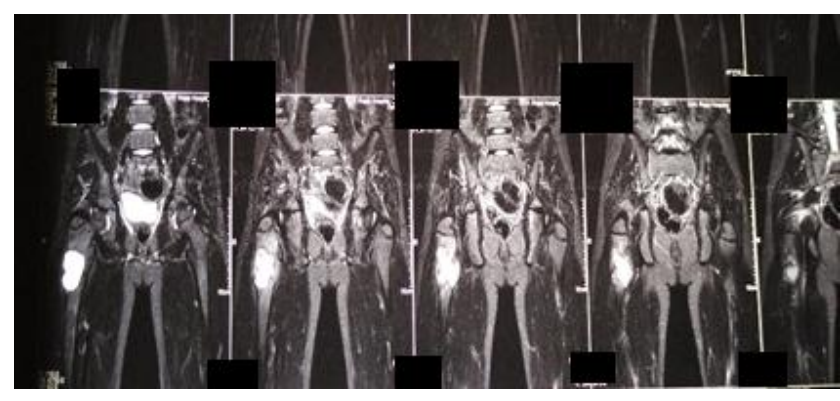

Figure 2

Financial or Other, Competing Interest: None.

Submission 11-07-2017, Peer Review 04-08-2017,

Acceptance 10-08-2017, Published 17-08-2017.

Corresponding Author:

Dr. D. Sivaraman,

\#14, Ponn Nagar, Therkku Kadu,

Attur-636102, Salem (D.T).

E-mail: siva326136@gmail.com

DOI: $10.14260 /$ jemds/2017/1037

(c) $\frac{10(3)}{\mathrm{BY} N \mathrm{ND}}$

\section{DIFFERENTIAL DIAGNOSIS}

The most important differential diagnosis are aneurysmal cysts, GCT, fibrous dysplasia.(4) The MRI shows low signal on T1- and high signal on T2-weighted scans. It can be helpful in distinguishing unicameral cysts from aneurysmal cysts, GCT, fibrous dysplasia and other benign lesions.

\section{PATHOLOGICAL DISCUSSION}

\section{Gross Appearance}

The bone displays an area of fusiform expansion. The periosteum lifts away easily and the underlying bone is eggshell thin, semitranslucent, bluish and easily penetrated. The cavity is a single chamber containing yellow fluid. Recent trauma may cause the fluid to become serosanguinous or haemorrhagic.(5) Following a healed fracture, the cavity may become divided by fibro-osseous septa. A thin layer of gray connective tissue lines, the inner surface of the cyst wall which displays multiple scroll-like ridges that account for the pseudoloculated appearance on roentgenograms.

\section{Microscopic Appearance}

The cyst wall is composed of layers of flattened cells (fibroblasts) lying on vascular collagenous or myxomatous tissue containing multinucleated giant cells, foam cells containing and lipids, and cholesterol crystals imbedded in fibrin.(6) The cortical wall composed of loosely trabeculated osseous tissue and many thin walled vessel. Following the trauma, periosteal new bone formation may be evident. In older subjects, the cyst gets solidified and filled with fibrous tissue.

\section{DISCUSSION OF MANAGEMENT}

Simple bone cysts are benign lesions in growing children. Some children with simple bone cysts sustain multiple fractures. Many children are fearful of subsequent fractures or are restricted from activity by their physicians. Families and surgeons would welcome a minimally invasive, low-risk treatment.(7) Treatment strategies for simple bone cysts include curettage and bone-grafting, intralesional injections, damage to the cyst wall and lining, decompression of the cyst, structural stabilisation or some combination of these methods. Substances that have been injected into cysts include methylprednisolone acetate, bone marrow, calcium sulphate pellets, demineralised bone matrix and calciumphosphate bone cement. Methods for damaging the cyst lining include scraping with needles or direct curettage. Decompression of the cyst can be performed with Kirschner wires or cannulated screws. Flexible intramedullary nails provide structural stability, but also disrupt the cyst lining and may decompress the cyst. Few comparative studies, however, have been done to directly evaluate treatment and consequently treatment varies widely. 
Corticosteroid injection was introduced as a treatment option for unicameral bone cysts in the mid-1970s, because the recurrence rate after curettage and bone grafting was approximately $50 \%$. Corticosteroid injection was described as an effective new treatment option that is inexpensive and involves less morbidity.(8)

\section{Surgical Technique}

The procedure is done with the patient heavily sedated or anaesthetised (Fig. no. 3). C-arm guidance is used to observe an 18-gauge spinal needle as it penetrates the cortex overlying the lesion at one end of the cyst; a second needle is placed at the opposite end (Fig. no. 5). The diagnosis of a unicameral bone cyst was confirmed by the efflux of straw coloured cyst fluid. With injection of methylprednisolone acetate with the use of two needle technique (Fig. no. 4). Patient received a total of three injections at two weeks interval, each consisting of $120 \mathrm{mg}$ methylprednisolone acetate.(8) Patient was discharged next day itself following each injections. The followup and monitoring was done by clinical symptomatology relief( ${ }^{(9)}$ and plain radiographs. This technique is believed to work either by an antiprostaglandin effect or by decreasing the pressure of the cyst.

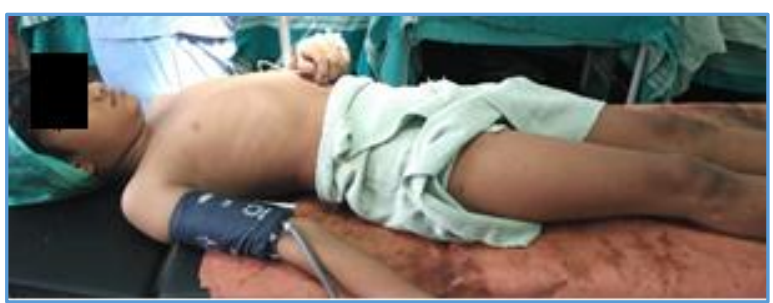

Figure 3

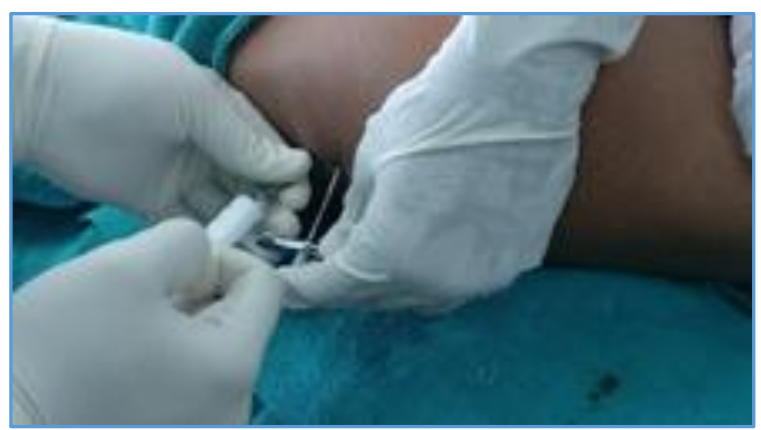

Figure 4

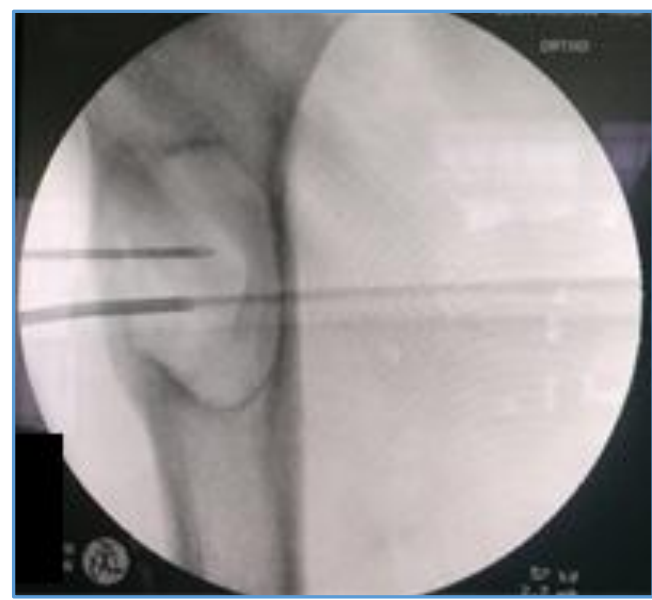

Figure 5

\section{Followup Evaluation}

After 5 months followup (Fig. No. 6), patient now become pain free and without limping. Radiologically, lytic area of proximal femur become consolidated, ossified without any pathological fractures.

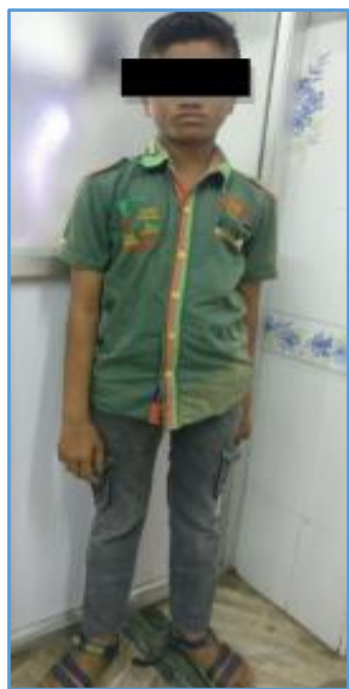

Figure 6

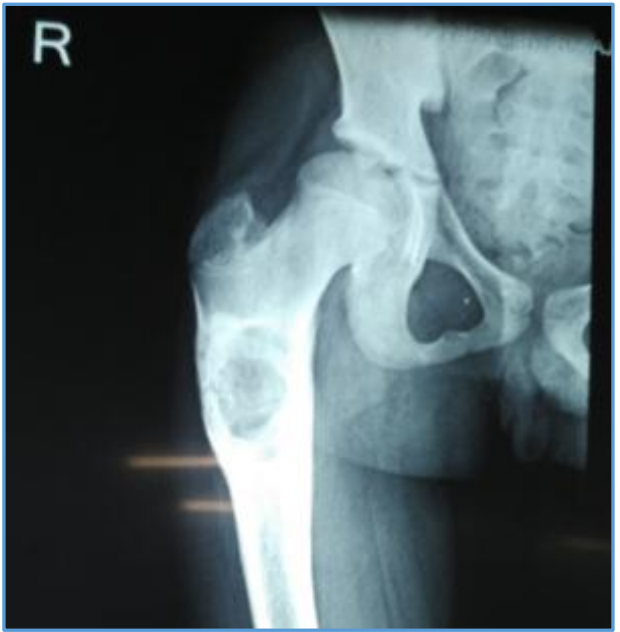

2 Months Follow-Up

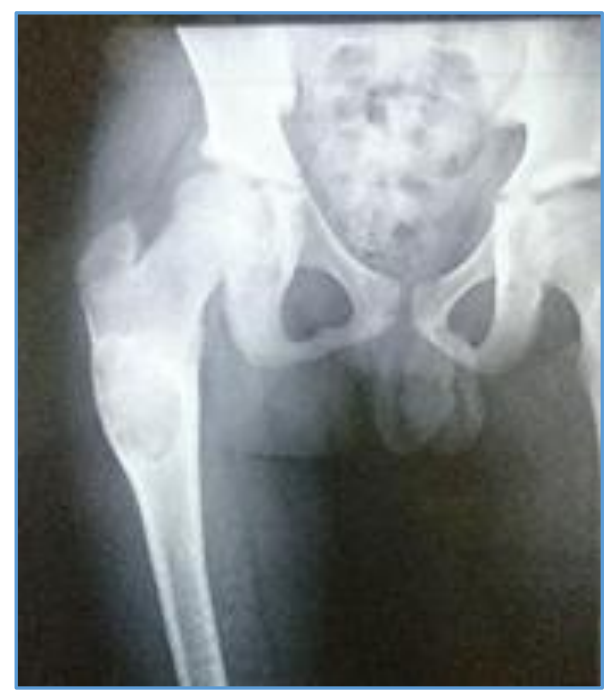

5 Months Follow-Up 


\section{RESULTS}

After 5 months followup, patient now become pain free and without limping. Radiologically, lytic area of proximal femur become consolidated, ossified without any pathological fractures.

\section{CONCLUSION}

Our results suggest that treatment with steroid injections offers satisfactory outcome in simple bone cysts in children in selective cases and thus is worthy of consideration before more aggressive methods are to be considered.

\section{REFERENCES}

[1] Capanna R, van Horn J, Ruggieri P, et al. Epiphyseal involvement in unicameral bone cysts. Skeletal Radiol 1986;15(6):428-32.

[2] Cohen J. Etiology of simple bone cyst. JBJS Am 1970;52(7):1493-7.

[3] Conway WF, Hayes CW. Miscellaneous lesion of bone. Radiol Clin North Am 1993;31(2):339-58.
[4] Moore TE, King AR, Travis RC, et al. Post traumatic cyst and cyst-like lesions of bone. Skelet Radiol 1989;18(2):93-7.

[5] Jaffe HL, Lichtenstein L. Solitary unicameral bone cyst with emphasis on the roentgen picture, the pathologic appearance, and the pathogenesis. Arch Surg 1942;44(6):1004-25.

[6] Morton KS. The pathogenesis of unicameral bone cyst. Can J Surg 1964;7:140-50.

[7] Neer CS, Francis KC, Marcove RC, et al. Treatment of unicameral bone cyst. A follow up study of one hundred seventy-five cases. JBJS Am 1966;48(4): 731-45.

[8] Yilmaz G, Aksoy MC, Alanay A, et al. Treatment of simple bone cysts with methylprednisolone acetate in children. Actaorthop Traumatol Turc 2005;39(5): 411-5.

[9] Baker DM. 16 Benign unicameral bone cyst. A study of forty-five cases with long-term follow up. Clin Orthop Relat Res 1970;71:140-51. 